\title{
Application of an O-ring pinch device as a constant-pressure inlet (CPI) for airborne sampling
}

\author{
Sergej Molleker ${ }^{1}$, Frank Helleis ${ }^{1}$, Thomas Klimach ${ }^{1}$, Oliver Appel $^{1,2}$, Hans-Christian Clemen ${ }^{1}$, Antonis Dragoneas ${ }^{1,2}$, \\ Christian Gurk ${ }^{1}$, Andreas Hünig ${ }^{1,2}$, Franziska Köllner ${ }^{1}$, Florian Rubach ${ }^{1,3}$, Christiane Schulz ${ }^{1,3}$, \\ Johannes Schneider ${ }^{1}$, and Stephan Borrmann ${ }^{1,2}$ \\ ${ }^{1}$ Max Planck Institute for Chemistry, Mainz, Germany \\ ${ }^{2}$ Institute for Atmospheric Physics, Johannes Gutenberg University, Mainz, Germany \\ ${ }^{3}$ Leibniz Institute for Tropospheric Research, Leipzig, Germany
}

Correspondence: Sergej Molleker (s.molleker@mpic.de) and Frank Helleis (frank.helleis@ mpic.de)

Received: 27 February 2020 - Discussion started: 11 March 2020

Revised: 27 May 2020 - Accepted: 12 June 2020 - Published: 8 July 2020

\begin{abstract}
We present a novel and compact design of a constant-pressure inlet (CPI) developed for use in airborne aerosol mass spectrometry. In particular, the inlet system is optimized for aerodynamic lenses commonly used in aerosol mass spectrometers, in which efficient focusing of aerosol particles into a vacuum chamber requires a precisely controlled lens pressure, typically of a few hectopascals. The CPI device can also be used in condensation particle counters (CPCs), cloud condensation nucleus counters (CCNCs), and gas-phase sampling instruments across a wide range of altitudes and inlet pressures. The constant pressure is achieved by changing the inner diameter of a properly scaled O-ring that acts as a critical orifice. The CPI control keeps air pressure and thereby mass flow rate $\left(\approx 0.1 \mathrm{~L} \mathrm{~min}^{-1}\right)$ upstream of an aerodynamic lens constant, deviating at most by only $\pm 2 \%$ from a preset value. In our setup, a pressure sensor downstream of the O-ring maintains control of the pinch mechanism via a feedback loop and setpoint conditions are reached within seconds. The device was implemented in a few instruments, which were successfully operated on different research aircraft covering a wide range of ambient pressures, from sea level up to about $55 \mathrm{hPa}$. Details of operation and the quality of aerosol particle transmission were evaluated by laboratory experiments and in-flight data with a single-particle mass spectrometer.
\end{abstract}

\section{Introduction}

There is a growing field of airborne atmospheric measurements of aerosol particles performed in earth science applications (Fuzzi et al., 2015). It is of major interest to study the chemical composition of aerosol particles, which, among other methods, can be investigated by mass spectrometry. Improvements regarding electronics, size, and weight (still in the range of $75-250 \mathrm{~kg}$ ) enabled online in situ mass spectrometry on many airborne platforms covering a wide altitude range. These instruments, using either laser ablation (Murphy and Thomson, 1995; Zelenyuk et al., 2015) or thermal vaporization (Aerodyne Aerosol Mass Spectrometer AMS; Drewnick et al., 2005; Canagaratna et al., 2007), commonly rely on an aerodynamic lens (Liu et al., 1995; Kamphus et al., 2008) to permit and focus aerosol particles into the vacuum chamber. Aerodynamic lenses are designed for a narrow range of lens pressures $\left(P_{\text {lens }}\right)$, which depend on the desired size range of aerosol particles. Before constantpressure devices were developed, fixed critical orifices were used, appropriately sized in diameter for either sea level pressure or a pressure at a certain flight altitude of interest. For deviating inlet pressures, this requires correction of the flow rate and size-dependent particle transmission. Such postflight data evaluation is based on laboratory calibrations (Bahreini et al., 2003). This approach introduces uncertainties and is not optimal for quantitative measuring instruments, for instance of the AMS type, which already rely on many other calibrations, such as for collection efficiency, ionization ef- 


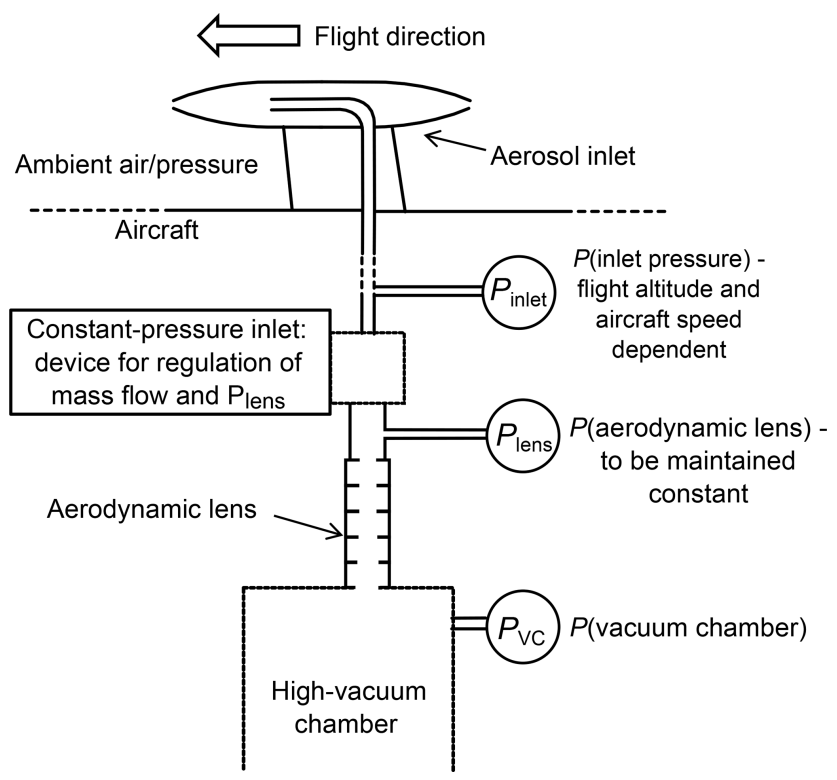

Figure 1. The position of a constant-pressure inlet (CPI) device in the sampling path is indicated in the drawing. The CPI is located upstream of an aerodynamic lens. Bypass flow or manifolds to other instruments are omitted. The task of the CPI device is to keep the pressure at the aerodynamic lens constant $\left(P_{\text {lens }}\right)$, regardless of changes in the inlet pressure $\left(P_{\text {inlet }}\right)$.

ficiency, lens transmission, focusing, and alignment. Also, the time-of-flight method for obtaining individual vacuum aerodynamic diameters of aerosol particles, as integrated on some instruments, relies on a known and preferably constant lens pressure. Hence, it is desirable to actively maintain the lens pressure at a constant value, independent of the ambient and inlet pressure and thus of flight altitude. A configuration of a constant-pressure inlet within an aircraft is indicated in Fig. 1. One alternative solution is to introduce an intermediate pressure volume downstream of a critical orifice. This volume is differentially pumped to keep it and the lens at a constant pressure. In the initial demonstration of such a design (Bahreini et al., 2008), a minimum pressure altitude of $600 \mathrm{hPa}$ was considered. In following airborne applications, successful measurements at altitudes up to $12 \mathrm{~km}$ (Schmale et al., 2010) and up to $7.7 \mathrm{~km}$ (Pratt et al., 2010) were reported. The advantages and limitations of such differentially pumped volume systems are discussed in Sect. 6. In our different approach, a very compact constant-pressure inlet (CPI) setup (without additional pumping or bypass flow) was developed and flight proven for single-particle-type and flashvaporization-type instruments, at altitudes from ground level up to $20 \mathrm{~km}$ (e.g., Köllner et al., 2017; Schulz et al., 2018; Höpfner et al., 2019; Dragoneas et al., 2020; Schneider et al., 2019).

\section{Principle of operation and technical description}

The idea behind our CPI design is a realization of a critical orifice of variable diameter by a flexible O-ring. The constant pressure inside the aerodynamic lens implies a constant mass flow rate of air (assuming constant air temperature). The mass flow rate through a critical orifice is proportional to its cross-section area and upstream pressure. Therefore, to maintain a constant mass flow over a wide range of ambient pressures, for instance between 1000 and $60 \mathrm{hPa}$, the circular cross-sectional area of the orifice has to change by a factor of approximately $16.7(1000 / 60)$. This corresponds to a factor of about 4.1 in change in diameter. Aerosol mass spectrometers typically require a fixed orifice of $0.1 \mathrm{~mm}$ diameter at sea level pressure (e.g., Jayne et al., 2000; Drewnick et al., 2005; Zelenyuk et al., 2009). Hence, the inner diameter of the relaxed O-ring has to be 0.4 to $0.5 \mathrm{~mm}$ and should shrink down to $0.1 \mathrm{~mm}$ through pinching. The initial design started with commercial O-rings of $0.8 \mathrm{~mm} \times 2 \mathrm{~mm}$ (inner diameter $\times$ cross section) dimensions, acquired from the company Dichtelemente arcus GmbH, Germany. The outer diameter of the pinch O-ring (i.e., the tube's cross section) was chosen to be relatively large, as it enables higher relative shrinking of the O-ring's inner opening. Models such as the FKM, FPM75, or MVQ70 (abbreviation indicates elastomer type and Shore hardness) were tested for particle measurements (black and red variants in Fig. 2). As a next step, custom made O-rings with dimensions of $0.5 \mathrm{~mm} \times 2.1 \mathrm{~mm}$ and $0.4 \mathrm{~mm} \times 2.15 \mathrm{~mm}$ were produced for improving the particle transmission (for the same mechanical setup that fixes and holds the O-ring). Two-component polymerizing silicon rubber from the company Zhermack SpA, Italy, with a Shore hardness of 50 (blue O-rings in Fig. 2) emerged to be a more suitable material regarding orifice shape during compression as compared to softer elastomers. The production method of the O-ring was highly reproducible. The same mold was reused in the production of numerous O-rings, while the specification of the silicon rubber states a reproduction detail of $2 \mu \mathrm{m}$. The shape of the pinched orifice is critical for avoiding significant particle losses, as discussed in the following section.

The O-ring is mounted inside a cylindrical recess within a tilting lever, which pushes the O-ring against the surface of a counterpart. In our case, this counterpart is a plate welded on top of a $1 / 4^{\prime \prime}$ plug valve block (see principal operation drawing in Fig. 3). To minimize the probability of turbulence around the O-ring's orifice, the openings of the housing, both upstream and downstream of the O-ring $\left(D_{\text {bore }}\right)$, are designed to be as large as possible. Yet the openings must still be small enough for a sufficient airtight support surface for the O-ring to be left. In the presented version, both diameters ( $\left.D_{\text {bore }}\right)$ are $1 \mathrm{~mm}$. Initially, the length of both bore holes in the described setup was $1.5 \mathrm{~mm}$, but it was further reduced to 0.5 or $1 \mathrm{~mm}$ in newer designs. Downstream of the O-ring, the tube expands conically at $45^{\circ}$ to $4.2 \mathrm{~mm}$ (i.e., the clear diameter of 


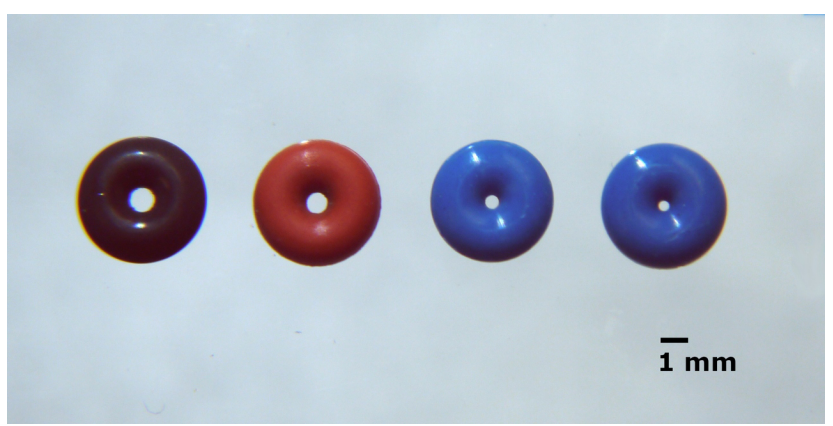

Figure 2. Photographs of pinch O-rings used during development of the CPI. The black and red O-rings (left) are the initially adopted commercially available O-rings of $0.8 \mathrm{~mm} \times 2.0 \mathrm{~mm}$ (inner diameter $\times$ cross section), with a Shore hardness of 75 (FPM) and 70 (MVQ), respectively. The blue O-rings (right) with 0.5 and $0.4 \mathrm{~mm}$ inner diameters were produced in the laboratory out of twocomponent silicone rubber with a Shore hardness of 50 . The $0.5 \mathrm{~mm}$ inner-diameter O-ring was chosen as the optimal solution for the flight altitude of up to $20 \mathrm{~km}$ (minimum inlet pressure) and lens pressures used in the instruments of the research group. On the right-hand side a $1 \mathrm{~mm}$ scale is shown.

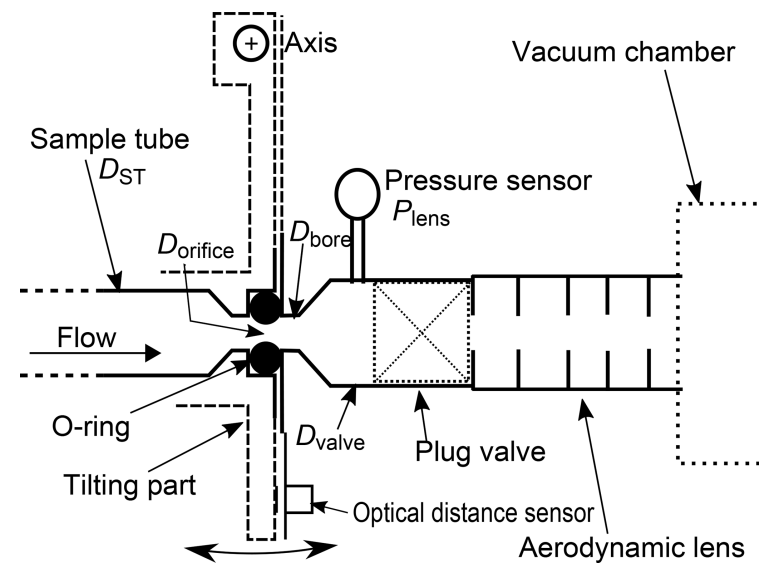

Figure 3. Principal drawing of the CPI design. The tilting part can be moved by a motor pulling it over a spindle mechanism. The controller uses the output of a pressure sensor downstream of the O-ring $\left(P_{\text {lens }}\right)$, as indicated in the drawing. An additional optical distance sensor between the tilting part and the valve block is used to ensure safe stop limits for the movement. Relevant inner diameters for sample flow are denoted with $D_{\mathrm{ST}}(2 \mathrm{~mm}), D_{\text {bore }}(1 \mathrm{~mm}), D_{\text {orifice }}$ (variable), and $D_{\text {valve }}(4.2 \mathrm{~mm})$.

the $1 / 4^{\prime \prime}$ plug valve in Fig. 3). In the most recent mechanical design (not used for characterization here), the downstream tube expands directly from the O-ring from 2 to $39 \mathrm{~mm}$ at an angle of $5.6^{\circ}$ conically. This is to further reduce radial flow velocities due to jet expansion at the exit of the critical orifice (Hwang et al., 2015).

The sample tube upstream of the $D_{\text {bore }}$ tube has an inner diameter $\left(D_{\mathrm{ST}}\right)$ of $2.05 \mathrm{~mm}\left(1 / 8^{\prime \prime}\right.$ o.d. tube). The tilting part of the O-ring's housing (lever) is pivoted, and its axis is de- signed to be $10 \mathrm{~mm}$ away to ensure that the deviations from the parallel configuration of the surfaces compressing the $\mathrm{O}$ ring remain small. Tilting the lever squeezes the O-ring and its inner opening. The pinching movement is driven by a motor, which pulls the lever via a spindle. The opposite, the relaxation movement, is supported by the spring force of the $\mathrm{O}$-ring and an additional spring.

A custom-made electronic control unit drives the motor until a preset lens pressure is reached. The control loop uses the output of a lens pressure sensor as feedback. In the presented example (ERICA instrument; Hünig et al., 2020), good results were obtained with an absolute pressure sensor (CMR373 model, Pfeiffer Vacuum GmbH, Germany), with a range of $0-10 \mathrm{hPa}$ and $0.15 \%$ accuracy. The feedback of the control unit was configured only with the integrative component (in PID terminology, proportional-integralderivative): the speed of the servomotor is proportional to the deviation from the set lens pressure. Good control stability of the lens pressure was demonstrated throughout the duration of longer flights on several aircraft (on the DLR HALO G550, AWI Polar 6 DC-3, Myasishchev M-55 Geophysica, NASA DC-8, and DLR Dassault Falcon 20). Pressure deviations were within $\pm 2 \%$, including ascent or descent rates of up to $30 \mathrm{~m} \mathrm{~s}^{-1}$ on the M-55 aircraft. Figure 4 illustrates the CPI-controlled lens pressure during one of the flights in which altitudes of up to $20 \mathrm{~km}$ were reached. As shown in the graph, the inlet tube pressure decreased down to $64 \mathrm{hPa}$, a value close to the estimated maximum possible aperture for the $0.5 \mathrm{~mm}$ inner diameter O-ring. In this condition, at minimum inlet pressure, some of the prepinching is retained to ensure an airtight sealing by the O-ring between the inlet and cabin air.

The plug valve, as indicated in Fig. 3, is built as part of the CPI system but is independent from the feedback control. The position of the lens pressure sensor between the Oring and the valve adds safety for the vacuum system during opening (and closing) of the inlet line in the following way: after closing or at the closed position of the valve, a rise in the lens pressure forces the feedback control to shrink the O-ring to its (set) minimum. Therefore, at the moment of the opening of the valve, only a low and safe flow rate can enter the vacuum chamber before the control starts to increase the $\mathrm{O}$ ring's aperture to reach a set lens pressure within about 15 $20 \mathrm{~s}$. The pinching movement has stop points at both travel ends. These limits are defined by the voltage output of an optical distance sensor measuring the distance to the pinching lever. This provision prevents overloading of the motor at maximum compression and as a backup prevents the mechanism from opening too far, which might result in leakage of laboratory or cabin air into the sample line. 


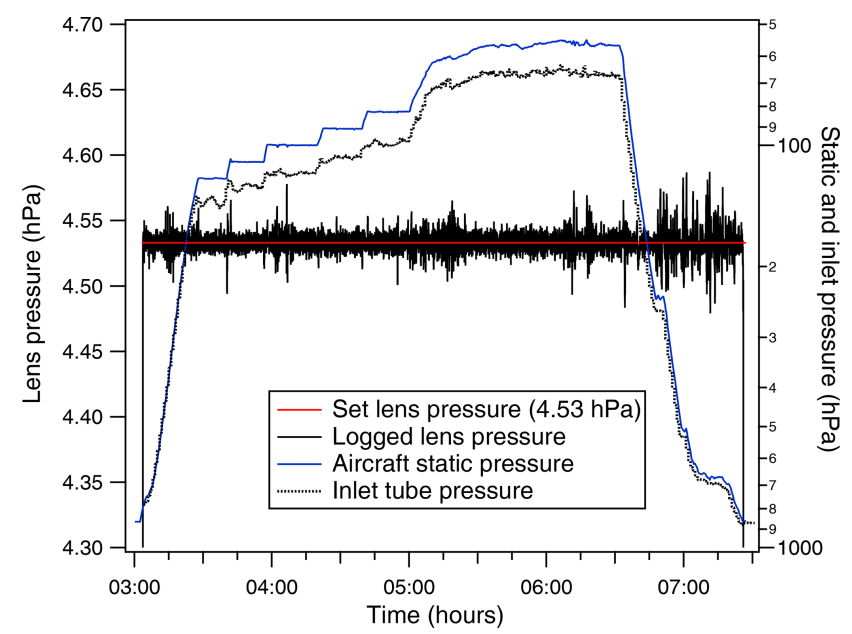

Figure 4. Stable CPI operation in the ERICA instrument is demonstrated by the recorded lens pressure aboard the M-55 Geophysica aircraft (StratoClim Project, flight on 27 August 2017). The maximum deviation of the lens pressure from the set value is $1.2 \%$. The flight was chosen for its high maximum altitude (GPS) of $20.45 \mathrm{~km}$ with a minimum inlet pressure of $64 \mathrm{hPa}$ and ambient pressure of $55 \mathrm{hPa}$ (the difference is caused by the dynamic pressure). Time is UTC.

\section{Visual inspection of the pinched O-ring}

With aerosol mass spectrometry as the main application in mind, the CPI performance has to be assessed by the quality of particle transmission in combination with an aerodynamic lens. As shown in Fig. 4, the performance regarding lens pressure stability meets the requirements. Initial particle transmission measurements with the commercial $0.8 \mathrm{~mm}$ inner-diameter O-ring revealed high particle losses. The highest losses of up to about $80 \%$ (for $350 \mathrm{~nm}$ sized ammonium nitrate particles) were observed for a high degree of pinching at sea level pressure, while for lower inlet pressure (i.e., less pinching), the particle transmission improved significantly and yielded results comparable with those of a fixed-orifice configuration. The transmission losses were preliminarily evaluated by comparing the overall transmission and bulk ionization efficiency of a flash-vaporization mass spectrometer (AMS instrument) to identical AMS configurations equipped with fixed-orifice inlets. The behavior of high particle transmission loss could be explained by further investigation of the shape of the O-ring's aperture during pinching.

For this purpose, photographs (such as those illustrated in Fig. 5) were taken with a long-working-distance $(70 \mathrm{~mm}) \mathrm{mi}-$ croscope looking through the O-ring pinched inside the CPI device. At sea level pressure, where the state of pinching was previously known by the recorded signal of the distance sensor, the $0.8 \mathrm{~mm}$ O-ring underwent a deformation into a narrow-slit shape (upper left panel in Fig. 5a). At lower inlet pressure, and consequently less pinching, the same O- ring regains its round shape. Here, the visible aperture area roughly corresponds to the area needed for the given mass flow. Obviously, the $0.8 \mathrm{~mm}$ diameter is unnecessarily large, and some of the compression can be avoided by starting with a smaller inner diameter. Additionally, a softer elastomer material was expected to be better for keeping the O-ring's aperture smoother and rounder. Therefore, 0.5 and $0.4 \mathrm{~mm}$ inner diameter O-rings were produced in machined molds using off-the-shelf two-component silicon rubber. Two different materials with Shore hardness of 50 and 22 were tested, with the latter showing less suitable properties. Figure $5 \mathrm{~b}$ illustrates the behavior of the $0.5 \mathrm{~mm}$ O-ring (shore 50). When pinching the aperture down to the state at sea level pressure, the aperture resembles a triangle. A perfect circularity under the maximum pinching state is not possible (top panels of Fig. 5b). However, this does not appear to be a prerequisite for good particle transmission. Also, with the same pinching mechanics, the maximum pinching states of a few O-rings from the same production batch showed exactly the same triangular deformation when observed under the microscope. Successive transmission efficiency measurements gave values similar to those measured by a fixed-orifice setup. The same behavior was exhibited by the $0.4 \mathrm{~mm}$ inner diameter version. However, in order to keep the following calibrations more general, a $0.5 \mathrm{~mm}$ O-ring was chosen for use in all of the instruments of the research group, as it was more suitable for the maximum expected flight altitude.

Prior to field deployment with stratospheric flights, laboratory tests (with the $0.5 \mathrm{~mm}$ O-ring) were performed with inlet pressure down to $55-60 \mathrm{hPa}$ (lower right picture in Fig. 5b). Notably, the lit area or the aperture of the $1000 \mathrm{hPa}$ photograph (Fig. 5b, top left) has about the area of a $0.1 \mathrm{~mm}$ diameter orifice required for the same lens pressure. A comparison to the $0.8 \mathrm{~mm}$ O-ring at sea level pressure (Fig. 5a, top left) shows that, while it controls the same lens pressure and hence the same airflow, the aperture cross section must be similar. However, the aperture is hidden from the front view, because apparently the "slit aperture" has a warped shape, where most of the high particle loss occurred.

\section{Methods - laboratory characterization of particle transmission}

After optimizing the O-ring's pinching properties, particlesize-dependent transmission measurements were performed with a laboratory setup. The first experiments focused on conditions at sea level pressure, where according to first experience, high particle losses can occur due to deviations from the circular shape of the aperture and its minimum size. The work presented below utilizes an optical detection unit of the aerosol mass spectrometer ERICA (Hünig et al., 2020), which is a combination of a single-particle laser ablation ToF-MS and a flash-vaporization ToF-MS (time-offlight mass spectrometer). The aerodynamic lens used here 


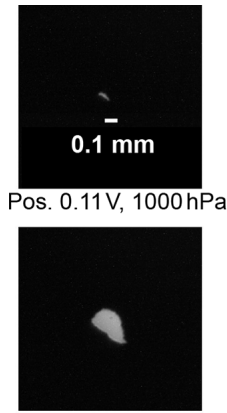

Pos. 0.28V

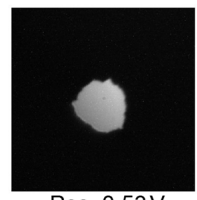

Pos. 0.53V

(a)
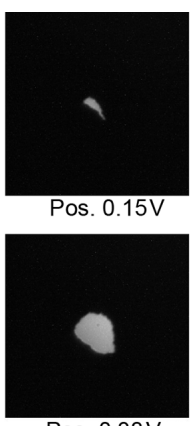

Pos. 0.38V

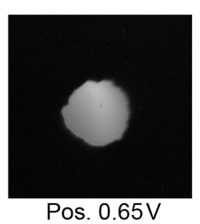

Pos. 0.65V
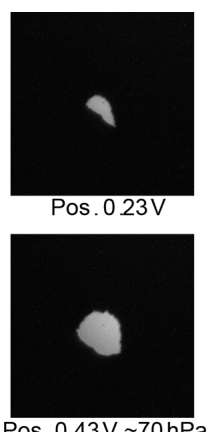

$0.43 \mathrm{~V} \sim 70 \mathrm{hPa}$

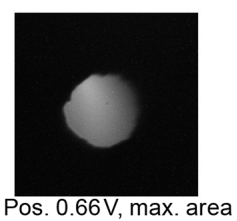

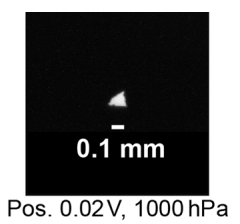

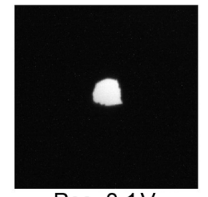

Pos. 0.1V

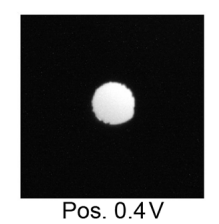

(b)
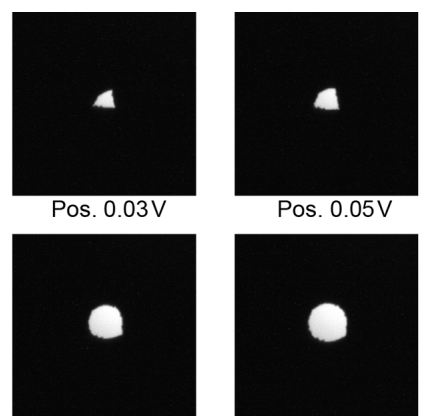

Pos. 0.2V
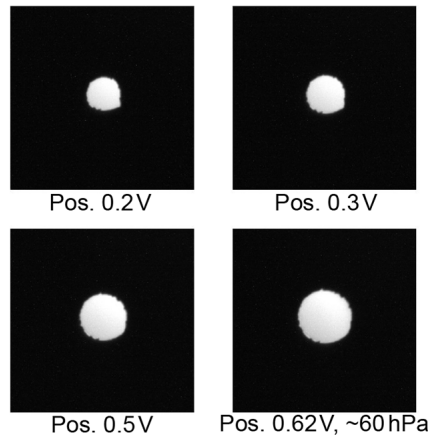

Pos. 0.3V

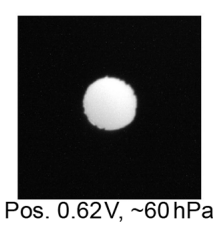

Figure 5. Microscope photographs of the O-ring aperture inside a backlit CPI device at different levels of pinching. The amount of pinching is recorded by a voltage output (see captions) of an optical distance sensor installed on the CPI's mechanics (Fig. 3). From the additionally logged inlet pressure during flight or laboratory experiments, the pinching position can be associated with a given inlet pressure. Exemplarily, pressure values of the desired limits $(1000$ to $60 \mathrm{hPa}$ or $70 \mathrm{hPa})$ are denoted for corresponding photographs. Panel (a) shows the initial setup with a commercial O-ring having dimensions of $0.8 \mathrm{~mm} \times 2 \mathrm{~mm}$. As seen in the minuscule (backlit) aperture area for sea level pressure $(1000 \mathrm{hPa})$, warping of the opening's shape and thus of the sample flow path can lead to high particle losses. Panel (b) shows the custommade optimized O-ring design with an inner diameter of $0.5 \mathrm{~mm}$.

was the intermediate pressure lens (IPL; Peck et al., 2016) optimized for $\mathrm{PM}_{2.5}$, a model from Aerodyne Research Inc. (MA, USA). In practice, the CPI's particle transmission can be tested only in combination with an aerodynamic lens, meaning that separate contributions of the individual components to particle losses are not directly accessible. The approach presented here is an absolute particle transmission measurement conducted in the same configuration for the CPI as for the fixed-orifice setup. The lens pressure for the CPI operation was set to $4.53 \mathrm{hPa}$, and a slightly different lens pressure of $4.41 \mathrm{hPa}$ was measured behind a $100 \mu \mathrm{m}$ fixed orifice. In both cases, sample flow rates were measured and taken into account (CPI $1.48 \mathrm{~cm}^{3} \mathrm{~s}^{-1}$; fixed $1.31 \mathrm{~cm}^{3} \mathrm{~s}^{-1}$ ). Particle-size-dependent transmission experiments were performed using polystyrene latex (PSL) beads, generated from a water solution (atomizer), with diameters between $200 \mathrm{~nm}$ and $5 \mu \mathrm{m}$. The number concentrations were referenced by a condensation particle counter (CPC; Model 5.403, GRIMM Aerosol Technik, Germany) for sizes of up to $800 \mathrm{~nm}$ or by an optical particle counter (OPC; GRIMM SkyOPC, Series 1.129; Bundke et al., 2015) for PSL sizes above or equal to $1000 \mathrm{~nm}$.

The applied optical detection unit and the measurement technique in the ERICA instrument are described in more detail in Hünig et al. (2020). The particle beam directed by the aerodynamic lens intercepts a perpendicular $\mathrm{CW}$ laser beam (blue light at $405 \mathrm{~nm}$ ) at a distance of $59 \mathrm{~mm}$. Here, the laser focus is adjusted to coincide with the focal point of the light-collecting elliptical mirror. The light scattered by individual aerosol particles is detected by a photomultiplier tube situated at the other focal point of the elliptical mirror. To obtain the total particle transmission of the aerodynamic lens, i.e., to not miss parts of the particle beam lost outside of the laser and mirror foci (below the detection threshold), the following method is applied. The aerodynamic lens is mechanically stepped to move the particle beam across the detection laser beam. Due to a relatively moderate focusing of the detection laser $(\approx 7 \mathrm{~mm}$ Rayleigh range $)$, the detection region along the laser beam axis is assumed to extend an order of magnitude more than across the beam (beam waist $\approx 60 \mu \mathrm{m}$ ). Therefore, scanning in one dimension is considered sufficient for PSL diameters larger than $200 \mathrm{~nm}$. For particle sizes below $150-200 \mathrm{~nm}$, the optical detection region decreases steeply, yielding only $1 \%-2 \%$ detection efficiency at $100 \mathrm{~nm}$. This prevents optical detection for transmission studies of particle sizes just above the detection threshold. The total transmission efficiency (TE) can be derived from the measured detection efficiency (DE) profile as a function of the lens position ( $x$ coordinate). For doing so, a simple but well-performing model was assumed by approximating the particle beam with a two-dimensional Gaussian profile of standard deviation $\sigma$ (Klimach, 2012). Since the scattered light pulses are recorded only above a certain intensity threshold, the detection probability is approximated by a rectangular top-hat function of the width $2 r_{L}$. The measured detection efficiency corresponds to the convolution integral 




Figure 6. Two examples of detection efficiency measured by stepping the particle beam across a detection laser (and photomultiplier unit). Detection efficiency was calculated from photomultiplier counts of the optical detection stage normalized by external CPC or OPC concentration. Total particle transmission efficiency (TE) is obtained as a parameter of a fit function, which results from a convolution of the assumed Gaussian particle beam profile, and a rectangular function describing the detection threshold.

of both functions and is given in Eq. (1):

$\mathrm{DE}(x)=0.5 \mathrm{TE}\left(\operatorname{erf}\left(\frac{x+r_{L}-x_{0}}{\sqrt{2} \sigma}\right)-\operatorname{erf}\left(\frac{x-r_{L}-x_{0}}{\sqrt{2} \sigma}\right)\right)$.

Two examples of detection efficiency scans are shown in Fig. 6 together with the fitted functions (red) as described by Eq. (1). The error bars are based on the Poisson counting uncertainty in the detection unit and the external CPC or $\mathrm{OPC}$ instruments. Fit parameters are TE, $r_{L}, x_{0}$, and $\sigma$, with TE being the main result for lens transmission. If the particle beam is narrower than the optical detection region, the measured profile shows a pronounced plateau at a magnitude equal to the transmission efficiency (Fig. 6, CPI example). For scans with the particle beam width being comparable or larger than the detection width, the obtained TE differs from maximum detection efficiency. In most detection scans, the maximum detection efficiency and the fitted TE differed by less than $5 \%$.

Intuitively, the CPI performance is expected to improve with decreasing inlet pressure due to relaxation of the O-ring, which would regain a larger and smoother round shape. On the other hand, a decrease in inlet pressure enhances the effects of other factors such as the growing Cunningham slip correction factor $C$ and the increasing flow speed, in order to keep the mass flow constant. Both parameters lead to a larger Stokes number $S t$ as a measure of particle impaction losses. The effects on the Stokes number can be seen in Eq. (2), which is valid for the front side of the flat round orifice (Lee et al., 1993; Bahreini et al., 2008):

$S t=\frac{\rho_{\mathrm{p}} D_{\mathrm{p}}^{2} C U_{0}}{18 \mu D_{0}}$

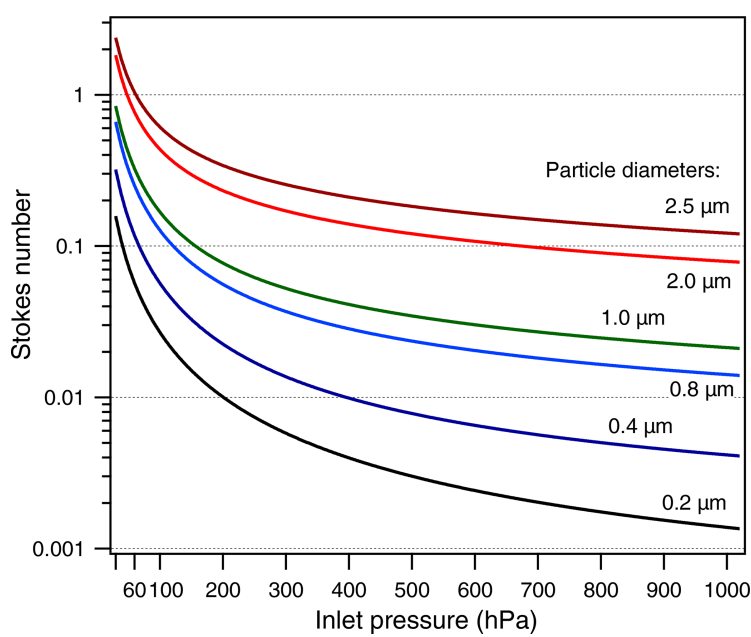

Figure 7. Stokes number calculated for different particle diameters as a function of inlet pressure in the range between 30 and $1020 \mathrm{hPa}$, with CPI behavior of varying orifice diameter. A particle density of $1 \mathrm{~g} \mathrm{~cm}^{-3}$ is used (similar to that of polystyrene beads, which is $1.05 \mathrm{~g} \mathrm{~cm}^{-3}$ ). For other higher particle densities, the result can be upscaled proportionally.

with particle density $\rho_{\mathrm{p}}$, particle diameter $D_{\mathrm{p}}$, Cunningham slip correction factor $C$, sample air velocity upstream of the orifice $U_{0}$, dynamic air viscosity $\mu$, and orifice diameter $D_{0}$. The O-ring geometry represents a smoother obstacle for the air stream, such that Eq. (2) only provides an (upper) approximation for the Stokes number, which is still useful for dimensional analyses. By replacing all variables dependent on inlet pressure, such as orifice diameter, air velocity, and slip correction, Eq. (2) is evaluated in the pressure range from 30 to $1020 \mathrm{hPa}$ (Fig. 7). A few examples are calculated for different particles sizes, nominally of density equal to $1 \mathrm{~g} \mathrm{~cm}^{-3}$, and a $1 / 8^{\prime \prime}$ (o.d.) upstream sample tube. Since the Stokes number is proportional to particle density, results for higher densities can be easily estimated. The calculation suggests that for inlet pressures from sea level down to about $300 \mathrm{hPa}$, the Stokes number is below 0.1 , and therefore the losses for submicron particles should be low. Towards stratospheric inlet pressures $(150-60 \mathrm{hPa})$ the Stokes number increases rapidly, and significant particle loss at diameters of about $1 \mu \mathrm{m}$ and above can be expected.

To obtain particle transmission at lower inlet pressure, i.e., to simulate flight conditions, a $250 \mu \mathrm{m}$ diameter orifice was placed upstream of a differentially pumped volume. Downstream of the low-pressure volume, sampling lines to the CPI, i.e., mass spectrometer, and a SkyOPC were connected via a Y-manifold. Measurements with the CPI system were performed at a few different values of inlet pressure, reducing pressure in steps by about a factor of 2 , such that pressures of $380,250,125$, and $65 \mathrm{hPa}$ were tested. The highest pressure in this procedure was chosen to be below $500 \mathrm{hPa}$, i.e., $380 \mathrm{hPa}$, in order to also fall within 
the condition for critical flow $\left(P_{\text {downstream }}<0.5 P_{\text {upstream }}\right)$ at the pressure-reducing orifice. This way, the sampled flow and hence particle losses from the particle generation to the pumped volume can be assumed as being nearly constant (for all tested values of inlet pressure). Additionally, care was taken to run and observe the particle generation at a constant concentration (well within $2 \%$ ) during experiments. The latter effort was made due to a lack of a reliable particle concentration reference within the low-pressure setup; although the SkyOPC is designed for measurements at low inlet pressure (specified down to $125 \mathrm{hPa}$ ), the changes in measured particle concentration appeared to be higher than is acceptable for use as a reference. Only the (absolute) transmission value at $380 \mathrm{hPa}$ was obtained by referencing photomultiplier counts to the external SkyOPC. From there on, for every particle size, inlet pressure was varied in steps down to $65 \mathrm{hPa}$ and raised back again to $380 \mathrm{hPa}$. At every pressure step, time was given for the CPI pinching mechanism to adjust, and then particle counts with statistically sufficient time were recorded by the mass spectrometer's optical detection unit (at the lens position of maximum detection). Transmission values were obtained as changes relative to the starting point.

\section{Particle transmission results}

Detection scans were performed for various PSL particle sizes at ground pressure (with the laboratory at $130 \mathrm{~m}$ above sea level). The resulting transmission efficiencies for both setups, the CPI O-ring and a fixed $100 \mu \mathrm{m}$ orifice setup, are summarized for comparison in Fig. 8. The following contributions to the error bars are included: uncertainty in the fitted TE parameter $(1 \%-5 \%)$, particle-counting uncertainty $(<2 \%)$, sample flow uncertainty $(3 \%)$, and the uncertainty in the tube loss correction in the tubing to the OPC for sizes above $1 \mu \mathrm{m}$ (e.g., $44 \%$ for $5 \mu \mathrm{m}$ particle diameter). The transmission efficiency is mainly defined by the performance of the lens and compares well to results of the same lens design published in Xu et al. (2017). The transmission values of the CPI are within uncertainties, close to those of a fixed orifice. As expected from a simple model of Stokes number dependence (Eq. 2, Fig. 7), the decreasing inlet pressure leads to a reduction in particle transmission. The same transmission data are plotted (for tested particle sizes) as a function of pressure in Fig. 9. The results in Fig. 9 also reflect the measurement procedure, for which the inlet pressure was varied in steps for the same particle size. The general behavior confirms the theoretic expectation of decreasing particle transmission with decreasing inlet pressure. The transmission efficiency for $200 \mathrm{~nm}$ diameters appears not to be affected by the increasing Stokes number. Some steps down in pressure show an opposite effect, i.e., a slight increase in particle transmission. This can most likely be attributed to the effect of an improving O-ring opening geometry, transform-

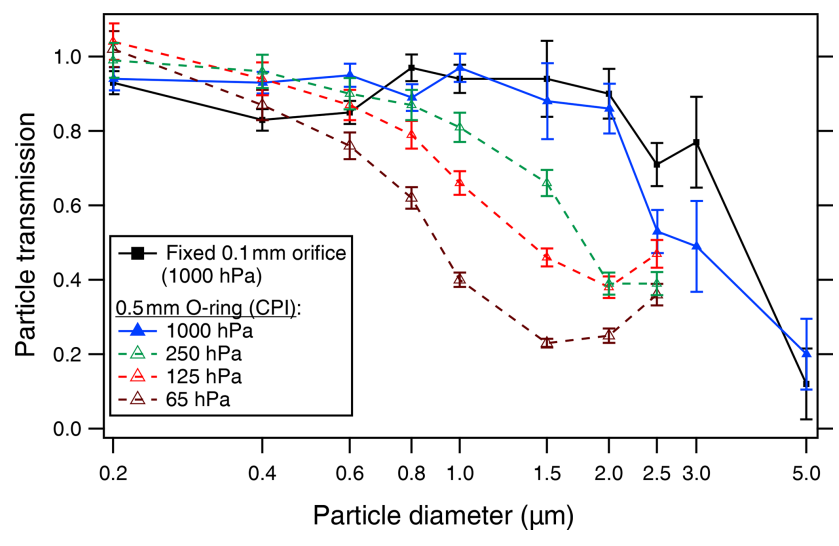

Figure 8. Transmission of PSL particles through the CPI device (blue line) and an aerodynamic lens in comparison to the same aerodynamic lens with a fixed $0.1 \mathrm{~mm}$ diameter critical orifice (black line). Filled data markers denote results at $1000 \mathrm{hPa}$ inlet pressure. Error bars include statistical particle-counting uncertainty, as well as uncertainties in the fitted function parameters and tube loss corrections. Open markers denote results for inlet pressures of 250 , 125 , and $65 \mathrm{hPa}$. Measurements were also performed for $380 \mathrm{hPa}$ but are not included here for clarity.

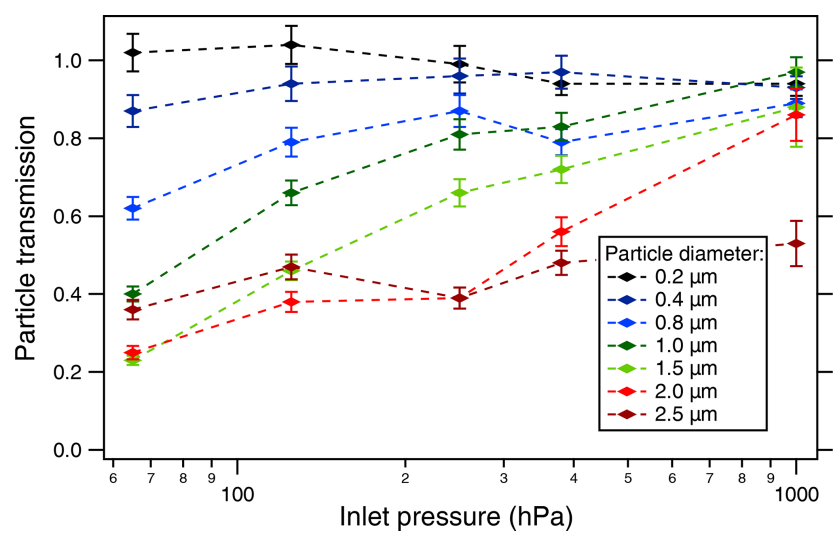

Figure 9. Transmission of PSL particles through the CPI device and an aerodynamic lens as a function of inlet pressure. Different PSL particle sizes from 0.2 to $2.5 \mu \mathrm{m}$ were used in this experiment. Error bars include statistical particle-counting uncertainty and the uncertainty in the maximum detection-to-transmission difference.

ing from a shape resembling a triangle to a circular aperture. An additional explanation leading to the same effect is that the impaction losses on the expansion side, downstream of the O-ring, would be lower with the higher particle's inertia.

\section{Summary and discussion}

A successful operation of the presented O-ring-based constant-pressure inlet device has been demonstrated through suitable laboratory characterization and aircraft field experiments. An inlet pressure range between sea level and 
down to $65 \mathrm{hPa}$ was covered with a single properly dimensioned O-ring. The CPI setup is compact: it adds only about $6 \mathrm{~cm}$ to the length on top of an aerodynamic lens. Also, good stability with a deviation of less than $1.2 \%$ from the preset lens pressure ( 2.5 to $5 \mathrm{hPa}$, depending on the instrument and aerodynamic lens was demonstrated during research flights on several research aircraft (DLR HALO G550, Myasishchev M-55 "Geophysica", NASA DC-8).

The same O-ring used for the transmission study of this paper was installed in the ERICA instrument during three aircraft field experiments (of 125 flight hours) over a period of about 2 years. Because the instrument was sitting idle in the lab with a closed inlet for most of this time, the O-ring was also experiencing a maximum pinching state. It appeared that the elasticity of the silicon rubber remained in good condition during the 2-year period, and no degradation of particle transmission with the same O-ring was found. The experience with different O-rings from the same production method showed that the exact reproducibility of the pinching shape is not mandatory, as long as the particle transmission quality remains as expected at ground-level pressure (under strong pinching). This has to be confirmed by measurement after new O-ring installation. With these considerations, further measurements at lower inlet pressure are less critical, because the O-ring relaxes towards its original, more circular shape. Here, the particle transmission is limited by other (reproducible) factors, such as lower air density and the same fixed geometry for the flow. So far, a few O-rings made for other instruments of the research group have shown very similar transmission efficiencies (TE $>85 \%$ ) at sea level pressure for submicron particles and hence have been kept for further usage.

Results of particle transmission obtained in the laboratory show that for inlet pressure down to $250 \mathrm{hPa}$, which is within the maximum altitude of most passenger-type research aircraft (e.g., $\approx 195 \mathrm{hPa}$ ambient pressure at $12 \mathrm{~km}$ altitude and $\approx 60 \mathrm{hPa}$ of dynamic pressure at $210 \mathrm{~m} \mathrm{~s}^{-1}$ flight speed), transmission of submicron aerosol particles remains larger than $80 \%$, with little difference to transmission at ground level. For a higher flight altitude and aerodynamic particle diameters larger than $0.6-0.8 \mu \mathrm{m}$, particle transmission reduces noticeably, and corrections should be applied. Nevertheless, even at the lowest designed and flight-proven inlet pressure of $65 \mathrm{hPa}$, the CPI's particle transmission performance can be well suited for stratospheric applications, where particle diameters are mostly below $0.6-0.8 \mu \mathrm{m}$. In cases of larger particles, especially with respect to mean volume diameters (e.g., particles of fresh volcanic origin at stratospheric altitudes; Wilson et al., 1993), one has to account for the evaporation of the particle's water content and other volatile species in the inlet tubing upstream of the CPI. This effect leads to smaller aerodynamic diameters and effectively improves the particle transmission through the CPI if one were judging by the ambient sizes. If used with a focus on even smaller particle sizes, in the nanometer-size range, a high transmission efficiency is well maintained. This is attributed to the fact that impaction losses due to the particles' inertia are low, and diffusion losses are negligible due to the CPI's small internal volume.

For comparison, particle losses considered in this publication also occur with alternative pressure-reducing inlet devices, such as the setup with the fixed diameter orifice introduced in Bahreini et al. (2008), where a differentially pumped volume at an intermediate constant pressure is utilized as "representative" pressure. The O-ring-based setup avoids the additional critical orifice (prone to particle losses) needed to create such an intermediate pressure step and eliminates the additional time spent by trace gases exposed to additional surfaces. Additionally, in the case of a minimum inlet pressure of $65 \mathrm{hPa}$, the pressure at the intermediate volume has to be set at about $30 \mathrm{hPa}$, which implies even higher Stokes numbers and particle losses at the constant-diameter orifice upstream of the lens. In future designs, the geometry for the flow around the O-ring can be further optimized (e.g., small-angle conical diffusors can be placed on both sides) to further improve the particle transmission of the CPI.

The CPI device was also applied in a gas-phase sampling instrument, in this case a proton transfer reaction mass spectrometer (PTR-MS; Jordan et al., 2009), in which a reaction drift tube in the inlet path requires a constant pressure of $2.2 \mathrm{hPa}$. Furthermore, other particle-counting instruments relying on constant pressure in either their inlet or their condensation cell, such as condensation particle counters (CPCs) or cloud condensation nucleus counters (CCNCs) can be equipped with the O-ring-based CPI system. A CCN-200 (Droplet Measurement Technologies, Longmont, CO, USA) is already in use with the presented CPI system (Andreae et al., 2018). However, it utilizes a different O-ring, with a controlled downstream pressure of about $200 \mathrm{hPa}$ and an airflow of an order of magnitude higher.

Data availability. Data can be provided on request from corresponding authors.

Author contributions. SM conducted laboratory characterization and field testing, designed and produced custom-made O-rings, made all figures, and wrote the manuscript with all the authors' contributions and comments. FH proposed and developed the CPI system. TK developed hardware. AD and OA developed data acquisition software and characterization methods. CG developed control electronics. OA, H-CC, AD, AH, FK, and CS were involved in laboratory and field testing and data analysis. FR contributed to hardware development and its testing. JS conducted the first field testing and initiated laboratory characterization. SB was involved in the initial designs and the manuscript drafting. All co-authors commented on the manuscript. 
Competing interests. The authors declare that they have no conflict of interest.

Acknowledgements. We are grateful for the work performed by the mechanical and electronic workshops of the Max Planck Institute for Chemistry and the mechanical workshop of the Institute for Atmospheric Physics of the University of Mainz. We also appreciate the work of the many people involved in the organization and conducting of several aircraft field campaigns where the CPI device was operated and tested. The characterization work was accomplished on the ERICA mass spectrometer, financed by the European Research Council (ERC) Advanced Grant of Stephan Borrmann (EXCATRO project, grant no. 321040). The work was supported by the Max Planck Society.

Financial support. This research has been supported by the FP7 Ideas program of the European Research Council (grant nos. EXCATRO 321040 and STRATOCLIM 603557), the BMBF (grant nos. joint project SPITFIRE - 01LG1205A - and ROMIC initiative), and the DFG (grant nos. SCHN 1138/2-2, BO 1829/9-1, and WI 1449/24-1).

The article processing charges for this open-access publication were covered by the Max Planck Society.

Review statement. This paper was edited by Charles Brock and reviewed by Fred Brechtel and one anonymous referee.

\section{References}

Andreae, M. O., Afchine, A., Albrecht, R., Holanda, B. A., Artaxo, P., Barbosa, H. M. J., Borrmann, S., Cecchini, M. A., Costa, A., Dollner, M., Fütterer, D., Järvinen, E., Jurkat, T., Klimach, T., Konemann, T., Knote, C., Krämer, M., Krisna, T., Machado, L. A. T., Mertes, S., Minikin, A., Pöhlker, C., Pöhlker, M. L., Pöschl, U., Rosenfeld, D., Sauer, D., Schlager, H., Schnaiter, M., Schneider, J., Schulz, C., Spanu, A., Sperling, V. B., Voigt, C., Walser, A., Wang, J., Weinzierl, B., Wendisch, M., and Ziereis, H.: Aerosol characteristics and particle production in the upper troposphere over the Amazon Basin, Atmos. Chem. Phys., 18, 921-961, https://doi.org/10.5194/acp-18-921-2018, 2018.

Bahreini, R., Jimenez, J. L., Wang, J., Flagan, R. C., Seinfeld, J. H., Jayne, J. T., and Worsnop, D. R.: Aircraft-based aerosol size and composition measurements during ACE-Asia using an Aerodyne aerosol mass spectrometer, J. Geophys. Res.-Atmos., 108, 8645, https://doi.org/10.1029/2002JD003226, 2003.

Bahreini, R., Dunlea, E. J., Matthew, B. M., Simons, C., Docherty, K. S., DeCarlo, P. F., Jimenez, J. L., Brock, C. A., and Middlebrook, A. M.: Design and Operation of a Pressure-Controlled Inlet for Airborne Sampling with an Aerodynamic Aerosol Lens, Aerosol Sci. Tech., 42, 465-471, https://doi.org/10.1080/02786820802178514, 2008.

Bundke, U., Berg, M., Houben, N., Ibrahim, A., Fiebig, M., Tettich, F., Klaus, C., Franke, H., and Petzold, A.: The IAGOS-CORE aerosol package: instrument design, operation and performance for continuous measurement aboard in-service aircraft, Tellus B, 67, 28339, https://doi.org/10.3402/tellusb.v67.28339, 2015.

Canagaratna, M., Jayne, J., Jimenez, J., Allan, J., Alfarra, M., Zhang, Q., Onasch, T., Drewnick, F., Coe, H., Middlebrook, A., Delia, A., Williams, L., Trimborn, A., Northway, M., DeCarlo, P., Kolb, C., Davidovits, P., and Worsnop, D.: Chemical and microphysical characterization of ambient aerosols with the aerodyne aerosol mass spectrometer, Mass Spectrom. Rev., 26, 185-222, https://doi.org/10.1002/mas.20115, 2007.

Dragoneas, A., Molleker, S., Appel, O., Hünig, A., Böttger, T., Hermann, M., Drewnick, F., Schneider, J., Weigel, R., and Borrmann, S.: An autonomous, aircraft-based, real-time aerosol mass spectrometry for stratospheric aerosol measurements, Atmos. Meas. Tech., in preparation, 2020.

Drewnick, F., Hings, S. S., DeCarlo, P., Jayne, J. T., Gonin, M., Fuhrer, K., Weimer, S., Jimenez, J. L., Demerjian, K. L., Borrmann, S., and Worsnop, D. R.: A New Time-of-Flight Aerosol Mass Spectrometer (TOF-AMS)-Instrument Description and First Field Deployment, Aerosol Sci. Tech., 39, 637658, https://doi.org/10.1080/02786820500182040, 2005.

Fuzzi, S., Baltensperger, U., Carslaw, K., Decesari, S., Denier van der Gon, H., Facchini, M. C., Fowler, D., Koren, I., Langford, B., Lohmann, U., Nemitz, E., Pandis, S., Riipinen, I., Rudich, Y., Schaap, M., Slowik, J. G., Spracklen, D. V., Vignati, E., Wild, M., Williams, M., and Gilardoni, S.: Particulate matter, air quality and climate: lessons learned and future needs, Atmos. Chem. Phys., 15, 8217-8299, https://doi.org/10.5194/acp15-8217-2015, 2015.

Höpfner, M., Ungermann, J., Borrmann, S., Wagner, R., Spang, R., Riese, M., Stiller, G., Appel, O., Batenburg, A. M., Bucci, S., Cairo, F., Dragoneas, A., Friedl-Vallon, F., Hünig, A., Johansson, S., Krasauskas, L., Legras, B., Leisner, T., Mahnke, C., Möhler, O., Molleker, S., Müller, R., Neubert, T., Orphal, J., Preusse, P., Rex, M., Saathoff, H., Stroh, F., Weigel, R., and Wohltmann, I.: Ammonium nitrate particles formed in upper troposphere from ground ammonia sources during Asian monsoons, Nat. Geosci., 12, 608-612, https://doi.org/10.1038/s41561-019-0385-8, 2019.

Hünig, A., Appel, O., Dragoneas, A., Molleker, S., Clemen, H.-C., Helleis, F., Klimach, T., Böttger, T., Drewnick, F., Schneider, J., and Borrmann, S.: Design, characterization, and first field deployment of a novel aerosol mass spectrometer combining the laser ablation and flash vaporization techniques, Atmos. Meas. Tech., in preparation, 2020.

Hwang, T.-H., Kim, S.-H., Kim, S. H., and Lee, D.: Reducing particle loss in a critical orifice and an aerodynamic lens for focusing aerosol particles in a wide size range of $30 \mathrm{~nm}-10 \mu \mathrm{m}, \mathrm{J}$. Mech. Sci. Technol., 29, 317-323, https://doi.org/10.1007/s12206-0141238-4, 2015.

Jayne, J. T., Leard, D. C., Zhang, X., Davidovits, P., Smith, K. A., Kolb, C. E., and Worsnop, D. R.: Development of an Aerosol Mass Spectrometer for Size and Composition Analysis of Submicron Particles, Aerosol Sci. Tech., 33, 49-70, https://doi.org/10.1080/027868200410840, 2000.

Jordan, A., Haidacher, S., Hanel, G., Hartungen, E., Märk, L., Seehauser, H., Schottkowsky, R., Sulzer, P., and Märk, T.: A high resolution and high sensitivity proton-transfer-reaction time-offlight mass spectrometer (PTR-TOF-MS), Int. J. Mass Spectrom., 286, 122-128, https://doi.org/10.1016/j.ijms.2009.07.005, 2009. 
Kamphus, M., Ettner-Mahl, M., Brands, M., Curtius, J., Drewnick, F., and Borrmann, S.: Comparison of Two Aerodynamic Lenses as an Inlet for a Single Particle Laser Ablation Mass Spectrometer, Aerosol Sci. Tech., 42, 970-980, https://doi.org/10.1080/02786820802372158, 2008.

Klimach, T.: Chemische Zusammensetzung der Aerosole: Design und Datenauswertung eines EinzelpartikelLaserablationsmassenspektrometers, Univ. Mainz, PhD Thesis, available at: http://nbn-resolving.org/urn:nbn:de:hebis:77-33547 (last access: July 2020), 2012.

Köllner, F., Schneider, J., Willis, M. D., Klimach, T., Helleis, F., Bozem, H., Kunkel, D., Hoor, P., Burkart, J., Leaitch, W. R., Aliabadi, A. A., Abbatt, J. P. D., Herber, A. B., and Borrmann, S.: Particulate trimethylamine in the summertime Canadian high Arctic lower troposphere, Atmos. Chem. Phys., 17, 1374713766, https://doi.org/10.5194/acp-17-13747-2017, 2017.

Lee, J.-K., Rubow, K. L., Pui, D. Y. H., and Liu, B. Y. H.: Design and Performance Evaluation of a Pressure-Reducing Device for Aerosol Sampling from High-Purity Gases, Aerosol Sci. Tech., 19, 215-226, https://doi.org/10.1080/02786829308959631, 1993.

Liu, P., Ziemann, P. J., Kittelson, D. B., and McMurry, P. H.: Generating Particle Beams of Controlled Dimensions and Divergence: I. Theory of Particle Motion in Aerodynamic Lenses and Nozzle Expansions, Aerosol Sci. Tech., 22, 293-313, https://doi.org/10.1080/02786829408959748, 1995.

Murphy, D. M. and Thomson, D. S.: Laser Ionization Mass Spectroscopy of Single Aerosol Particles, Aerosol Sci. Tech., 22, 237249, https://doi.org/10.1080/02786829408959743, 1995.

Peck, J., Gonzalez, L. A., Williams, L. R., Xu, W., Croteau, P. L., Timko, M. T., Jayne, J. T., Worsnop, D. R., Miake-Lye, R. C., and Smith, K. A.: Development of an aerosol mass spectrometer lens system for $\mathrm{PM}_{2.5}$, Aerosol Sci. Tech., 50, 781-789, https://doi.org/10.1080/02786826.2016.1190444, 2016.

Pratt, K. A., Twohy, C. H., Murphy, S. M., Moffet, R. C., Heymsfield, A. J., Gaston, C. J., DeMott, P. J., Field, P. R., Henn, T. R., Rogers, D. C., Gilles, M. K., Seinfeld, J. H., and Prather, K. A.: Observation of playa salts as nuclei in orographic wave clouds, J. Geophys. Res.-Atmos., 115, D15301, https://doi.org/10.1029/2009JD013606, 2010.

Schmale, J., Schneider, J., Jurkat, T., Voigt, C., Kalesse, H., Rautenhaus, M., Lichtenstern, M., Schlager, H., Ancellet, G., Arnold, F., Gerding, M., Mattis, I., Wendisch, M., and Borrmann, S.: Aerosol layers from the 2008 eruptions of Mount Okmok and Mount Kasatochi: In situ upper troposphere and lower stratosphere measurements of sulfate and organics over Europe, J. Geophys. Res.-Atmos., 115, D00L07, https://doi.org/10.1029/2009JD013628, 2010.
Schneider, J., Weigel, R., Klimach, T., Dragoneas, A., Appel, O., Hünig, A., Molleker, S., Köllner, F., Clemen, H.-C., Eppers, O., Hoppe, P., Hoor, P., Mahnke, C., Krämer, M., Rolf, C., Groos“s, J.-U., Zahn, A., Obersteiner, F., Ravegnani, F., Ulanovsky, A., Schlager, H., Scheibe, M., Diskin, G.-S., DiGangi, J., Nowak, J., Zöger, M., and Borrmann, S.: Aircraft-based observation of meteoric material in lower stratospheric aerosol particles between 15 and $68^{\circ} \mathrm{N}$, Earth and Space Science Open Archive, p. 26, https://doi.org/10.1002/essoar.10501338.1, 2019.

Schulz, C., Schneider, J., Amorim Holanda, B., Appel, O., Costa, A., de Sá, S. S., Dreiling, V., Fütterer, D., Jurkat-Witschas, T., Klimach, T., Knote, C., Krämer, M., Martin, S. T., Mertes, S., Pöhlker, M. L., Sauer, D., Voigt, C., Walser, A., Weinzierl, B., Ziereis, H., Zöger, M., Andreae, M. O., Artaxo, P., Machado, L. A. T., Pöschl, U., Wendisch, M., and Borrmann, S.: Aircraftbased observations of isoprene-epoxydiol-derived secondary organic aerosol (IEPOX-SOA) in the tropical upper troposphere over the Amazon region, Atmos. Chem. Phys., 18, 14979-15001, https://doi.org/10.5194/acp-18-14979-2018, 2018.

Wilson, J. C., Jonsson, H. H., Brock, C. A., Toohey, D. W., Avallone, L. M., Baumgardner, D., Dye, J. E., Poole, L. R., Woods, D. C., DeCoursey, R. J., Osborn, M., Pitts, M. C., Kelly, K. K., Chan, K. R., Ferry, G. V., Loewenstein, M., Podolske, J. R., and Weaver, A.: In Situ Observations of Aerosol and Chlorine Monoxide After the 1991 Eruption of Mount Pinatubo: Effect of Reactions on Sulfate Aerosol, Science, 261, 1140-1143, https://doi.org/10.1126/science.261.5125.1140, 1993.

Xu, W., Croteau, P., Williams, L., Canagaratna, M., Onasch, T., Cross, E., Zhang, X., Robinson, W., Worsnop, D., and Jayne, J.: Laboratory characterization of an aerosol chemical speciation monitor with $\mathrm{PM}_{2.5}$ measurement capability, Aerosol Sci. Tech., 51, 69-83, https://doi.org/10.1080/02786826.2016.1241859, 2017.

Zelenyuk, A., Yang, J., Choi, E., and Imre, D.: SPLAT II: An Aircraft Compatible, Ultra-Sensitive, High Precision Instrument for In-Situ Characterization of the Size and Composition of Fine and Ultrafine Particles, Aerosol Sci. Tech., 43, 411-424, https://doi.org/10.1080/02786820802709243, 2009.

Zelenyuk, A., Imre, D., Wilson, J., Zhang, Z., Wang, J., and Mueller, K.: Airborne Single Particle Mass Spectrometers (SPLAT II \& miniSPLAT) and New Software for Data Visualization and Analysis in a Geo-Spatial Context, J. Am. Soc. Mass Spectr., 26, 257270, https://doi.org/10.1007/s13361-014-1043-4, 2015. 